\title{
Coulisses
}

Revue de théâtre

19| Hiver 1999

Varia

\section{La tranche des roses sont plus belles fanées}

Jacky Schwartzmann

\section{OpenEdition}

Journals

Édition électronique

URL : https://journals.openedition.org/coulisses/5855

DOI : $10.4000 /$ coulisses.5855

ISSN : 2546-9460

\section{Éditeur}

Presses universitaires de Franche-Comté

\section{Édition imprimée}

Date de publication : 1 janvier 1999

Pagination : 74-77

ISBN : 2-913322-09-3

ISSN : $1150-594 X$

Référence électronique

Jacky Schwartzmann, «La tranche des roses sont plus belles fanées », Coulisses [En ligne], 19| Hiver 1999, mis en ligne le 18 octobre 2019, consulté le 12 janvier 2022. URL : http://

journals.openedition.org/coulisses/5855; DOI : https://doi.org/10.4000/coulisses.5855

Ce document a été généré automatiquement le 12 janvier 2022.

Coulisses 


\title{
La tranche des roses sont plus belles fanées
}

\author{
Jacky Schwartzmann
}

$1^{e}$ prix régional, catégorie non-étudiants, au Grand Prix Universitaire de la Nouvelle 1998 dont le thème était « Jardins".

En 1999, le concours a pour thème «Erreur ». Envoyez vos textes au CROUS avant le 28 février!

119 heures. J'aime les morts. Je termine mon café. J'écrase ma cigarette. J'enfile un gros pull. Une veste. Je boutonne ma veste. Enfile un manteau. Lace mes chaussures. Ferme ma porte à clé. Descends les escaliers. Croise un voisin. Il tourne la tête. Salopard. Dans mon immeuble on ne m'aime pas. Ils n'osent pas me saluer. Et moi je voudrais les voir crever.

2 Arrêt du bus. J'attends celui de 19 heures 12. Une fausse bourgeoise attend également. Quand je me suis posé sur le banc elle s'est poussée sur le côté. Me balance de pauvres regards. Je sais, je sens qu'elle me craint. Ça pourrait m'amuser. Mais non. J'ai plutôt envie de lui déchirer le faciès. Comme déchirer la vulgaire page d'un magazine. Ou alors l'effrayer un bon coup, pour qu'une crise cardiaque lui écrase le cœur.

3 Le bus arrive. Je monte. L'autre aussi, la dinde. Le chauffeur m'ignore. Elle va s'asseoir loin de moi. Je n'attends absolument plus rien des gens. Le trajet est long. Nous traversons toute la ville. Terminus. Je descends. Fais deux cents mètres. La boutique de l'arabe. Lui, il me parle. Il n'a rien à me dire. Il me semble qu'il n'a rien à me dire. Je prends du pain. Un saucisson. Un litre de vin blanc. Je jette le fric. Je sors. Traverse la rue. Ouvre la grille. Entre. Ferme à clé derrière moi. Allée centrale. Je monte sur une centaine de mètres. La petite baraque. La clé. La porte. Portemanteau. J'accroche mon manteau. Il fait un froid de connards ici. Je suis fatigué. J'ai dormi toute la journée. Je dors le jour parce que je travaille la nuit. Je prends le bus de 19 heures 12. Bus. L'arabe. La boutique de l'arabe. Je traverse la rue. J'ouvre la grille. Vous savez ça: j'aime les morts.

421 heures. J'enfile mon manteau. Je sors. Je descends l'allée centrale. Première ronde de la nuit. Comme si je me baladais, mais je surveille. On m'a dit que ça faisait un peu moins d'un kilomètre. Je veux bien le croire. C'est un petit cimetière. Les âmes sont 
toutes immenses, mais bien serrées, elles tiennent. Elles tiennent sous les croix. Beaucoup de croix. Parce que la mort est une intersection. Une mathématique bleue. Fais mon tour. Ils sont tous là ces bâtards-morts. Absents lorsque j'appelle : c'est leur présence. Je les connais tous. Je ne pourrais pas vivre sans eux. Ils m'impressionnent. Une certaine ponctualité. Une droiture. Une objectivité. Une liberté, qu'ils ont. L'affranchissement. Terminé les conneries.

On mange des asticots paraplégiques. On boit la pluie qui traîne. On ne baise plus. Dieu n'assure pas le service après-vagin. Je les aime mes morts. M'appartiennent pas. Et je ne leur donne rien. Leurs crânes sont ailleurs, mais je m'arrange pour que les tombes soient propres. Tous mes clients sont tristes: aucun ne se plaint. Je nettoie leurs excréments. Les cadavres chient à la verticale. Ils balancent du malheur. Moi je passe au-dessus d'eux, j'avale la mélancolie de leurs flatulences. Je gère la dignité d'avoir vécu. Je suis le patron de la filiale prosaïque de la mort. Je ne fais pas ma ronde en moins de 30 minutes. Vérifie tout. Je veux pas que mes cadavres aient honte de leur costume. Je suis rigoureux. On me paye.

6 Termine ma ronde. Dernière tombe de ma ronde. Celle-là je la connais mieux que toutes les autres. C'est une fillette là-dessous. Elle a 10 ans. Un accident. Il y a une photographie sur l'érection tombale. Elle est splendide. Je passerais entre deux rangées d'anges sans les voir, tellement elle est belle. J'aurais aimé la voir mourir, voir son dernier regard. Le saisir, une fois pour toutes. Cette gosse tient mes neurones en laisse. Je suis heureux qu'elle soit là, vers moi, toutes les nuits. Elle parle des silences. Elle grignote des murmures. Elle n'a jamais de seins. Elle a le rêve givré. Elle a le sang cendre. Elle est couchée pour mieux être belle.

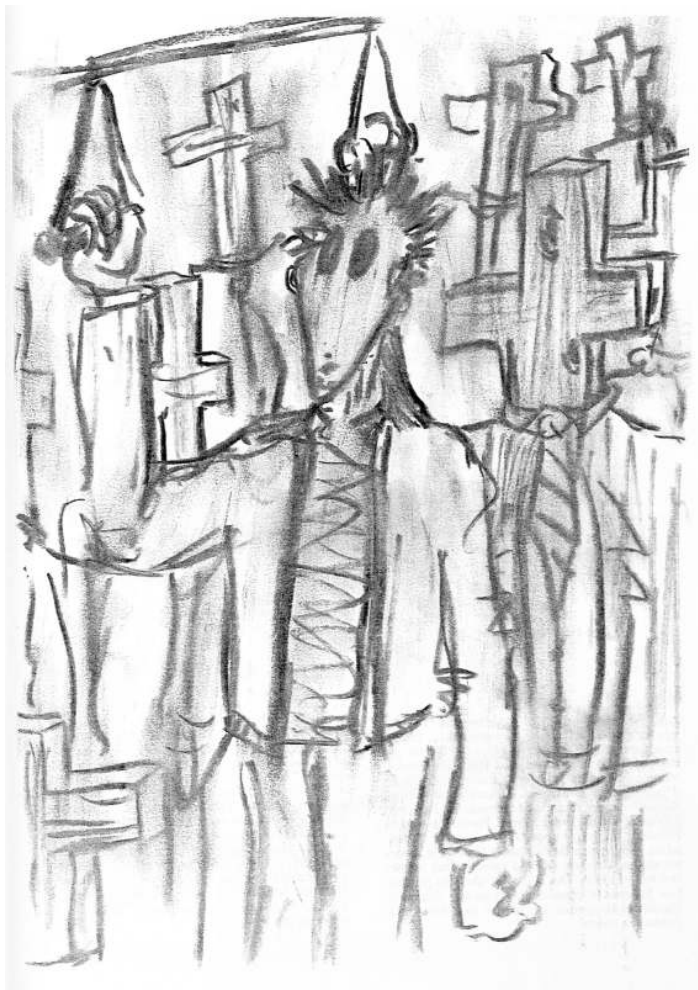

Dessin original Grégoire Kocjan

7 Le radiateur a bien chauffé. Portemanteau. Manteau. Le taux de mortalité c'est mon avenir. L'avenir est un flingue braqué sur le front. Je suis assis sur la frontière. Pour 
ceux qui vivent, je suis le pote des morts. Pour les morts, je suis un larbin. On ne m'aime pas, dans mon immeuble. On me croise. On baisse les yeux. On tord la bouche. Je gâche un paysage. Je saccage un équilibre. Les gens n'aiment pas mourir. Ils savent qu'un jour je m'occuperai d'eux, de leur costume de bois. Ils ne me veulent pas. Poinçonneur de l'au-delà. Il y a du napalm quand ils me regardent. Moi je réponds du givre. Je les déteste. Je les chie. La journée, je dors. Eux, ils galopent. Occupés. Sollicités. Excités. Ça m'échappe, cette course à connards. Me laissent à la traîne. Savent à peine que j'existe. Doux principes. Censure raisonnable. Société de martyrs. Couchés sous des lames de rasoirs. Piétinés par des colosses adroits et lourds. Mensonges et crédibilité. Adultère et coucheries. Vie et mort des images. Les icônes transpirantes dévorent les gens. Bande de gens. L'on craint ses propres enfants. Attachement. Statues monstrueuses. Dictateurs administratifs. Pirates commerciaux. Flics cervicaux implantés par dialyse. Symboles cancéreux. Rage officialisée. Verges et vagins pôles d'existence. Chercheurs d'or. Égouts. Buildings. Grandes succursales. Show-live de mœurs abominables. Dévorer. Dévorer. Gestes des ancêtres. Parole de vivant. Honneur. Nomades handicapés moteur. Sédentaires admirateurs de Rimbaud. Électricité à tous les étages. Des rats dans la cuisine. Des mémés froides au salon. Des étrangers dans les prisons. Les femmes s'ennuient. Aspiration. Descente. Espoirs et saloperies. On ne sort pas. Alors moi, j'aime les morts.

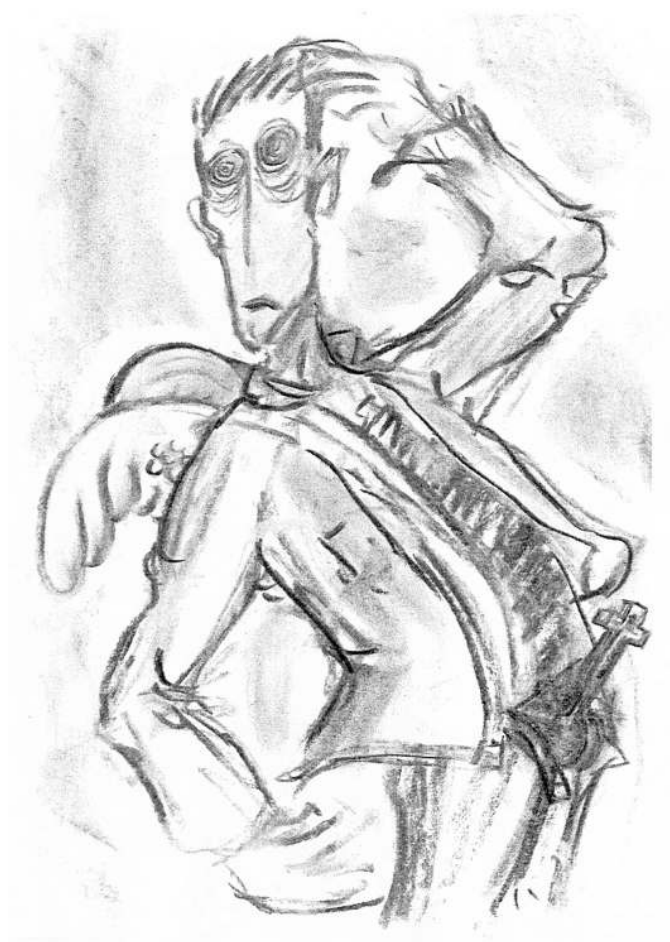

Dessin original Grégoire Kocjan

23 heures. Deuxième ronde. J'enfile mon manteau. Je trace dans les sillons du malheur. Je marche sur les larmes. Il n'y a pas d'odeur. Il fait froid. Je m'accroche à mon $37^{\circ}$ Celsius. Marcher c'est vivre. Vivre c'est nul. Vivre c'est dangereux pour la santé. On se durcit le synapse. Il cassera un jour. On sera pas là pour chialer. On sera mort et c'est bien. C'est pas cultuel. C'est un truc. La mort c'est un truc. Il n'y a pas de code barre dessus. Il n'y a plus de vigile. Il n'y a plus d'agios. La compétition est terminée. Nous 
sommes tous impétrants. Dernière tombe de la ronde. Fillette. 10 ans. Je t'aime. Je t'aime! Pas ma faute, le cœur, ça réfléchit pas.

Le radiateur déconne. Manteau portemanteau. Moi je ne sais pas réparer un radiateur. Je ne sais pas comment ça marche, la chaleur. J'enfile mon manteau. Je tape des pieds. Je grelotte. Marre. Et puis j'ai ma ronde à faire. 1 heure du matin. J'ai les pensées courbes. Je ne sers à rien dans ce cimetière. Les voleurs de cadavres ça n'existe pas. J'ai pas de Pétain dans mon registre. J'ai qu'une fillette. Je me vautre sur le caillou. Je crois que je pleure. La mort c'est un truc. Je mange du pain et du saucisson. J'ai déjà bu la moitié de ma bouteille. Je pense à un jardin. Les pierres tombales poussent droites et carrées. $\mathrm{Y}$ a pas d'engrais. $\mathrm{Y}$ a rien à tailler. $\mathrm{Y}$ a juste à planter les graines. Les graines c'est vous. Vous arrivez. Vous mûrissez. La mort fait son obscur travail en vous. Pourrissez, pourrissez... je vous attends.

10 La ronde est terminée. Putain de radiateur. Putain de froid. Mais qui, nom de dieu, qui a inventé c'te vie ?! On n'est jamais au courant de rien! On attend de crever et voilà, les hommes passent, les souvenirs sont trop maigres, et tchao! Pondez, pondez, chères femelles. Les trois ou quatre kilogrammes de viande vont grandir et pourrir et tchao! Certains disent que la vie c'est l'ensemble des forces vives qui résistent à la mort. Ceuxlà, je les renverse. Moi je vous le dis, vivre c'est crever, bien doucement, on a toute l'existence pour la sentir passer, la grande putain. La mort, c'est vous et à bientôt.

113 heures du matin. Pas un bruit. Même le vent est tricard. Le silence. Toujours le silence. On prend la mort comme un drame, alors on fait silence. Moi, à chaque enterrement, j'ai envie de hurler de joie, parce que ça fait un putain d'humain en moins. Il me tarde, le jour de l'apocalypse. Ce sera une simple mesure d'hygiène métaphysique. Épurer un peu l'Éternel. Torcher dieu, le grand con aveugle. Franchement, vous ne trouvez pas que l'existence méritait mieux que vous? J'ai mis des grands coups de pieds dans le radiateur. Marre de tout.

5 heures du matin. Dernière ronde. Rien n'a bougé. La fillette a toujours le sourire angélique. Je crache sur mon mouchoir et je frotte la photographie. Elle resplendit de bave. Elle me regarde. C'est déjà ça. Je regarde autour de moi. Personne. Je baisse ma braguette. Je saisis mon étalon. Masturbation. Les jumelles en spirales. Le plâtre qui monte. Je sens comme de l'électricité. Secousses. Décharges. Terminé. Jouissance : un subside en virement sur le sexe. 7 secondes d'éternité. J'arrose de sperme une jeune plante qui ne poussera plus. À demain mon fol amour. 


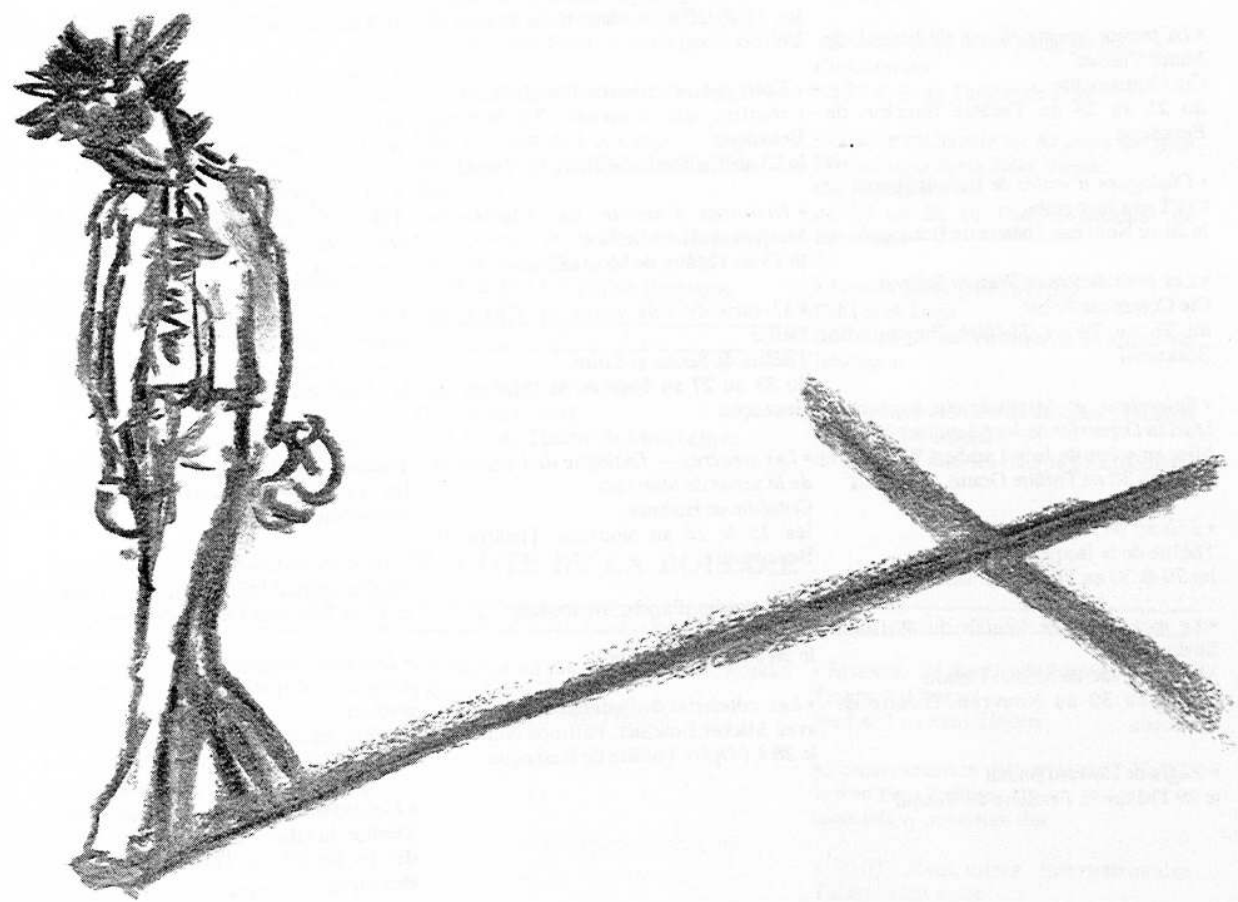

Dessin original Grégoire Kocjan 